\title{
Relationship between Perceived Health Status and Health Practices in the General Adult Population in Japan
}

\author{
Yukari Noguchi' ${ }^{1}$, Kimiyo Ueda ${ }^{2}, K^{\prime}$ miko Fukumoto ${ }^{3}$, Koichi Harada ${ }^{4}$, Atsushi Ueda ${ }^{2}$, \\ Chang-Nian Wei ${ }^{2}$ \\ ${ }^{1}$ Department of Health Sciences, Graduate School of Medical Sciences, Kyushu University, Fukuoka, Japan \\ ${ }^{2}$ Faculty of Life Sciences, Kumamoto University, Kumamoto, Japan \\ ${ }^{3}$ Kyushu University of Nursing and Social Welfare, Tomio Tamana, Kumamoto, Japan \\ ${ }^{4}$ Department of Medical Technology, Faculty of Health Science, Kumamoto Health Science University, \\ Kumamoto, Japan \\ Email: noguchi@hs.med.kyushu-u.ac.jp
}

Received 25 May 2015; accepted 23 June 2015; published 26 June 2015

Copyright (C) 2015 by authors and Scientific Research Publishing Inc.

This work is licensed under the Creative Commons Attribution International License (CC BY).

http://creativecommons.org/licenses/by/4.0/

C) (i) Open Access

\section{Abstract}

The objective of this study was to explore the relationship of perceived health status and Breslow's seven health Practices(7 - 8 hours of sleep per night, maintaining a healthy weight, moderate or no alcohol intake, regular physical activity, no eating between meals, eating breakfast, and having never smoked cigarettes) in adult residents in Kumamoto Prefecture Japan. We used 2011 data from the "Health Japan 21" program in Kumamoto Prefecture, a study consisting of 2519 adults aged from 20 - 74 years. Data for the study were gathered by questionnaire. The questionnaire was divided into following sections: perceived health status, seven health practices, life satisfaction, depression, social network, and demographic variables. We found that those groups engaged in more than four health practices had higher scores for perceived health status than those groups with less than four. Using Pearson's correlation coefficient, positive correlations were found between perceived health status and health practices $(r=0.229, p<0.001)$, life satisfaction $(r=$ $0.279, p<0.001)$, and social network $(r=0.089, p<0.001)$; negative correlations were found with age $(r=-0.058, p<0.01)$, body mass index (BMI) $(r=-0.093, p<0.001)$, and depression $(r=-0.109$, $p<0.001$ ). Furthermore, we clarified the differences in perceived health status by age and gender. The data from multiple regression analysis show an association between level of perceived health status and life satisfaction, the seven health practices, employment, age, depression, and social network. Our findings demonstrate a relationship between perceived health status and the seven health practices, and can be used to encourage healthier practices to enhance perceived health status and life satisfaction in community health care work. 


\section{Keywords}

\section{Perceived Health Status, Health Practices, Japanese Population}

\section{Introduction}

In 1972, Belloc and Breslow first reported a strong relationship between physical health status and seven lifestyle practices for physical health [1]. They found that these seven health practices were significantly associated with a general index of physical health. Breslow's seven health practices (7 - 8 hours sleep regularly, maintaining proper weight, moderate or no use of alcohol, regular physical activity, not eating between meals, eating breakfast, and never smoking cigarettes) are widely accepted in Western and Asian countries. Over the past 40 years in Japan, many studies have been published regarding such issues [2]-[7], and these seven health habits have been used to assess health practices and to test the association between health practices and health status, including depressive states and complaints [8]-[15]. Furthermore, the Japanese government's public health service policies and Health Japan 21 refer to these seven practices with respect to prevention of chronic disease and enhancement of quality of life in Japanese citizens [16] [17].

The World Health Organization's definition of health refers to the "complete status of physical, mental, and social well-being." This definition contrasts with early studies where health status was determined via mortality rates [18]-[20] and chronic conditions (physician ratings and functional ability) [21] [22]. Recently, perceived health has been used to measure health status [23] [24]. Kaplan et al. suggested that perceived health held the key to understanding other psychosocial influences on health. This is a simple, direct, and inclusive method, because it is based on the respondent's perceptions [25].

Several studies have reported an association between lifestyle and perceived health status by sex [26], age group [26]-[31] [34] [35], occupation [27] [28] [33], ethnicity [28] [30] [35], household income, different chronic conditions [34] [35], and personality traits [26] [36]. Despite such studies having clarified the overall associations among perceived health status (self-reported health status) and lifestyle (physical activity, drinking habits, smoking habits, eating habits, nutrition, driving safety, leisure-time activities, and intensity of each physical activity), surprisingly little is known about the relationship between Breslow's seven health practices and perceived health status.

In Lester and Breslow's research, physical health status was measured along a spectrum, ranging from severe disability, chronic conditions, impairment, symptoms, to high energy levels [37] [38]. However, it is difficult to use this measure in a community public health service. In the present study, we evaluated the usefulness of Breslow's seven health practices to subjectively assess physical and perceived health status, using a perceived health scale containing all seven health practices.

The purpose of this study was to explore the relationship between perceived health status and Breslow's seven health practices in the adult population of Japan, and to find effective and simple (low cost) suggestions of good daily life habits for health and longevity.

\section{Methods}

Data were gathered from the 2011 questionnaire research "Health Kumamoto 21". The present study was con ducted after receiving informed consent from the subjects and approval from the ethics committee of the Kumamoto University Faculty of Life Sciences (approval number 408). This study was performed in accordance with the Declaration of Helsinki.

\subsection{Study Population}

A cross-sectional research method was adopted. The data used in this study were sourced from the ongoing Health Japan 21 program in Kumamoto Prefecture, Japan. A total 5585 adult residents were selected on the basis of a stratified systematic sample of city housing units and using area probability sampling methods. Information for 2011 about health status and lifestyle was obtained from mail-back questionnaires. Completed questionnaires were received within 2 weeks from 2519 respondents (45.1\%), which included 1159 men and 1360 women aged 
between 20 and 74 years. To ensure anonymity, no name was required on the questionnaire. Table 1 lists demographic variables including sex, age, employment status, family structure, perceived health status, life satisfaction, depression, and social network, as well as Breslow's seven health practices. Employment status was rated on a 5-point scale: made redundant (1), unemployed (2), unstable employment (3), nonworking spouse and/or children (4), and employed (5). Perceived health status was measured by responses to the question, "All in all, would you say your health is excellent, good, fair, or poor?” [23]. Responses were rated on a 4-point scale: excellent (4), good (3), fair (2), or poor (1). Life satisfaction scores were measured by responses to the question, "How satisfied are you with your daily life?” [39]. Responses were rated on a 5-point scale: very dissatisfied (1), dissatisfied (2), neither dissatisfied nor satisfied (3), satisfied (4), or very satisfied (5). Depression scores were measured by responses to the question, "Do you feel any stress in your daily life?" [39]. Responses were rated on a 5-point scale: very strongly (1), strongly (2), neither stressed nor unstressed (3), slightly (4), or no stress (5). Social network participation was measured by a composite index of items relating to contact with friends and relatives, and membership in various kinds of group activities. Social network scores were based on three questions concerning the extent and frequency of three types of social ties (close friends/relations, involved in the

Table 1. Variables in the analyses of health practices and perceived health status.

\begin{tabular}{|c|c|c|}
\hline Variables & Categories & \\
\hline Sex & Men/women & Remarks \\
\hline Age & Years & \\
\hline Employment & Employed status & $\begin{array}{l}\text { Based on one question concerning the occupation status of five scores } \\
\text { of employment.: "made redundant (1), unemployed (2), unstable } \\
\text { employment (3), nonworking spouse and/or children (4), } \\
\text { and employed (5)" }\end{array}$ \\
\hline Family structure & $\begin{array}{l}\text { Single/couple family/tow-generation } \\
\text { family/three-generation family }\end{array}$ & \\
\hline $\begin{array}{l}\text { Perceived health } \\
\text { status }\end{array}$ & Excellent/good/fair/poor & $\begin{array}{l}\text { All in all, would you say your health is excellent, good, fair, or poor? } \\
\text { Responses were rated on 4-point scale from } \\
\text { "Excellent (4) to Poor (1)" }\end{array}$ \\
\hline Life satisfaction & $\begin{array}{l}\text { Very dissatisfied/dissatisfied/neither } \\
\text { satisfied nor } \\
\text { dissatisfied/satisfied/very satisfied }\end{array}$ & $\begin{array}{l}\text { How satisfied are you with your daily life? Response were rated on } \\
\text { 5-point scale from "Very dissatisfied (1) to very satisfied (5)" }\end{array}$ \\
\hline Depression & $\begin{array}{l}\text { Extremely stressed/very } \\
\text { stressed/“normal” stress le- } \\
\text { vels/slightly stress/no stress }\end{array}$ & $\begin{array}{l}\text { Do you feel any stress in your life? Response were rated on 5-point } \\
\text { scale from "Extremely stressed (1) to no stress (5)" }\end{array}$ \\
\hline Social network & & $\begin{array}{l}\text { Based on } 3 \text { questions concerning the extent and frequency of three } \\
\text { scores of social ties (close people, the role of community, and join } \\
\text { group activities). Responses were rated on } 3 \text { items out of a total of } 9 \\
\text { using a 3-point scale. }\end{array}$ \\
\hline \multicolumn{3}{|l|}{$\begin{array}{l}\text { Breslow’s seven } \\
\text { health practices: }\end{array}$} \\
\hline 7 - 8 h sleep per day & Yes/no & \\
\hline $\begin{array}{l}\text { Maintaining proper } \\
\text { weight }\end{array}$ & Yes/no & \\
\hline $\begin{array}{l}\text { Moderate or no use } \\
\text { of alcohol }\end{array}$ & Yes/no & \\
\hline $\begin{array}{l}\text { Regular physical } \\
\text { activity }\end{array}$ & Yes/no & \\
\hline $\begin{array}{l}\text { Not eating between } \\
\text { meals }\end{array}$ & Yes/no & \\
\hline Eating breakfast & Yes/no & \\
\hline $\begin{array}{l}\text { Having never } \\
\text { smoked cigarettes }\end{array}$ & Yes/no & \\
\hline
\end{tabular}


community, and joining group activities) [39]. Health practice status was based on Breslow’s seven health practices [1]. The health practice score represents the number of current health practices $(0-7)$. Participants selfreported their weight and height, which were used to calculate BMI.

\subsection{Analysis}

Data were analyzed using the IBM SPSS Statistical Package, Version 20.0 (IBM Corp., Armonk, NY, USA). Participants were divided into six age groups: 20 - 29, 30 - 39, 40 - 49, 50 - 59, 60 - 69, and 70 - 74 years of age. Participants were also was divided into three groups according to the number of regular health activities currently practiced: zero to three (0 - 3), four to five (4 - 5), and six to seven (6 - 7).

Differences in the percentages among the health practice groups, age groups, and sex groups were tested using chi-squared tests. Differences in mean values among health practices, age, and sex groups were tested for significance with one-way analysis of variance, multiple comparison procedures using Tukey's HSD test, and $t$-tests. Pearson's correlation analysis was used to determine the relationship among all associated variables. Multiple stepwise regression analysis was used to examine the effects of the independent variables (age, BMI, Breslow's health practices, life satisfaction, depression, social network, family structure, and employment status) on the levels of perceived health status. All data are given as mean $\pm \mathrm{SD}$. A p-value $<0.05$ was considered significant.

\section{Results}

Based on Breslow's seven health practices, 59.0\% of participants (men, 60.2\%; women, 57.9\%; p > 0.05) regularly had 7 - 8 hours sleep per night; 56.4\% (men, 55.1\%; women, 57.5\%; p > 0.05) maintained a proper weight; 86.6\% (men, 77.2\%; women, 94.4\%; p < 0.001) had moderate or no alcohol use; $26.5 \%$ (men, 29.6\%; women, 23.9\%; p < 0.05) engaged in regular physical activity; 37.6\% (men, 51.5\%; women, 26.0\%; p < 0.01) reported not eating between meals; $80.9 \%$ (men, $77.4 \%$; women, $83.8 \%$; $<<0.05$ ) reported eating breakfast every day; and $75.7 \%$ (men, 59.0\%; women, 89.7\%; $\mathrm{p}<0.001$ ) reported never smoking cigarettes.

Table 2 reports data for the age, sex, and health practice groups. Mean age did not differ between men and women for all age groups. The total percentage in the 4 - 5 health practices group (men, 45.0\%; women, 55.5\%)

Table 2. Demographic and participant groups $(\mathrm{n}=2519)$.

\begin{tabular}{|c|c|c|c|c|c|}
\hline \multirow{2}{*}{ Age } & \multirow{2}{*}{$\begin{array}{l}\text { Age (year) } \\
\text { Mean } \pm \text { SD }\end{array}$} & \multirow{2}{*}{$\begin{array}{c}\text { No. of respondents } \\
\text { n (\%) }\end{array}$} & \multicolumn{3}{|c|}{ No. of health practices n (\%) } \\
\hline & & & $0-3$ & $4-5$ & $6-7$ \\
\hline Men & $47.4 \pm 13.6$ & $1159(46.0)$ & $387(33.4)$ & $522(45.0)^{*}$ & $250(21.6)^{\# \$}$ \\
\hline $20-29 y$ & $24.5 \pm 3.1$ & $144(12.4)$ & $58(40.3)$ & $67(46.5)$ & $19(13.2)^{\# \$}$ \\
\hline $30-39 y$ & $34.6 \pm 2.9$ & $177(15.3)$ & $83(46.9)$ & $74(41.8)$ & $20(11.3)^{\# \$}$ \\
\hline $40-49 y$ & $44.7 \pm 3.0$ & $204(17.6)$ & $88(43.1)$ & $93(45.6)$ & $23(11.3)^{\# \$}$ \\
\hline $50-59 y$ & $55.0 \pm 2.8$ & $296(25.5)$ & $97(32.8)$ & $135(45.6)^{*}$ & $64(21.6)^{\# \$}$ \\
\hline $60-69 y$ & $62.8 \pm 2.1$ & $212(18.3)$ & $39(18.4)$ & $114(53.8)^{*}$ & $59(27.8)^{\# \$}$ \\
\hline $70-74 y$ & $71.5 \pm 1.4$ & $126(10.9)$ & $22(17.5)$ & $39(31.0)^{*}$ & $65(51.5)^{\# \$}$ \\
\hline Women & $46.8 \pm 13.7$ & $1360(54.0)$ & $340(25.0)$ & $755(55.5)^{*}$ & $265(19.5)^{\# \$}$ \\
\hline $20-29 y$ & $24.6 \pm 2.9$ & $179(13.2)$ & 55 (30.7) & $97(54.2)^{*}$ & $27(15.1)^{\# \$}$ \\
\hline $30-39$ y & $34.4 \pm 2.8$ & $228(16.8)$ & $61(26.8)$ & $139(61.0)^{*}$ & $28(12.2)^{\# \$}$ \\
\hline $40-49 y$ & $44.8 \pm 2.9$ & 249 (18.3) & $69(27.7)$ & $144(57.8)^{*}$ & $36(14.5)^{\# \$}$ \\
\hline $50-59 y$ & $55.8 \pm 3.0$ & 339 (24.9) & $85(25.1)$ & $198(58.4)^{*}$ & $56(16.5)^{\# \$}$ \\
\hline $60-69 y$ & $62.7 \pm 2.1$ & 229 (16.8) & $46(20.1)$ & $137(59.8)^{*}$ & $46(20.1)^{\#}$ \\
\hline $70-74 y$ & $71.6 \pm 1.4$ & $136(10.0)$ & 24 (17.7) & $40(29.4)^{*}$ & $72(52.9)^{\# \$}$ \\
\hline Total & $47.1 \pm 13.7$ & 2519 (100.0) & 727 (28.9) & $1277(50.7)^{*}$ & $515(20.4)^{\# \$}$ \\
\hline
\end{tabular}

${ }^{*} \mathrm{p}<0.01,4$ - 5 vs. 0 - 3; ${ }^{*} \mathrm{p}<0.05,6$ - 7 vs. 0 - 3; ${ }^{\mathrm{s}} \mathrm{p}<0.05,6$ - 7 vs. 4 - 5; Significant differences measured using chi-squared test. 
was significantly higher than the 0 - 3 (men, 33.4\%; women, 25.0\%) and 6 - 7 (men, 21.6\%; women, 19.5\%) groups for both men and women ( $\mathrm{p}<0.05)$.

Tables 3-5 report data of perceived health status, life satisfaction, and BMI according to health practice, sex, and age groups. For both men and women, mean scores of perceived health status in the groups of $4-5$ and 6 - 7 current health practices were significantly higher than those in the 0 - 3 group, and the $6-7$ group was significantly higher than the 4 - 5 group. There were no significant differences between men and women or among age groups (Table 3). As for perceived health status data, the life satisfaction mean scores of the groups who engaged in 4 - 5 and 6 - 7 practices were significantly higher than those of the 0 - 3 group, and the 6 - 7 group was significantly higher than the 4 - 5 group. The total life satisfaction mean score for women was significant higher than that for men. There were no significant differences among age groups for men and women (Table 4). The total mean BMI variable was significantly higher in the 0 - 3 group than the 4 - 5 and 6 - 7 groups, and the 4 - 5 group was significantly higher than the 6 - 7 group. Furthermore, mean scores of the variables perceived health,

Table 3. Scores of perceived health status by health practices, age, and sex groups.

\begin{tabular}{|c|c|c|c|c|c|c|c|}
\hline $\begin{array}{l}\text { Number of health } \\
\text { practices }\end{array}$ & Total & $20-29 y$ & $30-39 y$ & $40-49 y$ & $50-59 y$ & $60-69 y$ & $70-74 y$ \\
\hline \multicolumn{8}{|c|}{ Men } \\
\hline $0-3$ & $2.06 \pm 0.77$ & $2.19 \pm 0.71$ & $2.10 \pm 0.74$ & $2.03 \pm 0.81$ & $2.02 \pm 0.85$ & $1.97 \pm 0.67$ & $2.00 \pm 0.76$ \\
\hline $4-5$ & $2.38 \pm 0.85^{\mathrm{c}}$ & $2.54 \pm 0.80^{c}$ & $2.54 \pm 0.81^{\mathrm{c}}$ & $2.29 \pm 0.77$ & $2.41 \pm 0.90^{\mathrm{c}}$ & $2.26 \pm 0.87$ & $1.89 \pm 0.78$ \\
\hline $6-7$ & $2.60 \pm 0.82^{\mathrm{ab}}$ & $3.11 \pm 0.74^{\mathrm{ab}}$ & $2.90 \pm 0.79^{a}$ & $2.43 \pm 0.95^{\mathrm{a}}$ & $2.63 \pm 0.83^{\mathrm{a}}$ & $2.44 \pm 0.70^{\mathrm{a}}$ & $2.27 \pm 0.80$ \\
\hline Total & $2.31 \pm 0.84$ & $2.47 \pm 0.81$ & $2.37 \pm 0.82$ & $2.20 \pm 0.82$ & $2.33 \pm 0.90$ & $2.26 \pm 0.80$ & $2.12 \pm 0.77$ \\
\hline F value & $30.760^{* * *}$ & $10.857^{* * *}$ & $11.263^{* * * *}$ & $3.392^{*}$ & $10.456^{* * *}$ & $4.056^{*}$ & 0.692 \\
\hline \multicolumn{8}{|c|}{ Women } \\
\hline $0-3$ & $2.14 \pm 0.78$ & $2.00 \pm 0.77$ & $2.28 \pm 0.84$ & $2.19 \pm 0.81$ & $2.12 \pm 0.75$ & $2.09 \pm 0.72$ & $2.00 \pm 0.85$ \\
\hline $4-5$ & $2.40 \pm 0.85^{c}$ & $2.57 \pm 0.85^{c}$ & $2.47 \pm 0.79$ & $2.40 \pm 0.85^{\mathrm{c}}$ & $2.26 \pm 0.87$ & $2.43 \pm 0.86^{\mathrm{c}}$ & $2.10 \pm 0.99$ \\
\hline $6-7$ & $2.64 \pm 0.81^{\mathrm{ab}}$ & $2.89 \pm 0.80^{\mathrm{a}}$ & $2.61 \pm 0.92$ & $2.69 \pm 0.82^{\mathrm{a}}$ & $2.64 \pm 0.86^{\mathrm{ab}}$ & $2.54 \pm 0.75^{\mathrm{a}}$ & $2.50 \pm 0.60$ \\
\hline Total & $2.37 \pm 0.84$ & $2.44 \pm 0.87$ & $2.43 \pm 0.82$ & $2.39 \pm 0.84$ & $2.29 \pm 0.85$ & $2.38 \pm 0.82$ & $2.33 \pm 0.72$ \\
\hline F value & $24.705^{* * * *}$ & $13.111^{* * *}$ & 1.832 & $4.435^{*}$ & $6.820^{* *}$ & $4.201^{*}$ & 1.610 \\
\hline
\end{tabular}

${ }^{\mathrm{a}} \mathrm{p}<0.05,6$ - 7 vs. 0 - 3; ${ }^{\mathrm{b}} \mathrm{p}<0.05,6-7$ vs. $4-5$; ${ }^{\mathrm{p}} \mathrm{p}<0.05,4-5$ vs. $0-3$; ${ }^{* *} \mathrm{p}<0.01 ;{ }^{* * *} \mathrm{p}<0.001$; Significant differences among the health practices groups measured using Tukey's HSD test.

Table 4. Scores of life satisfaction by health practices, age, and sex groups.

\begin{tabular}{|c|c|c|c|c|c|c|c|}
\hline $\begin{array}{c}\text { Number of health } \\
\text { practices }\end{array}$ & Total & $20-29 y$ & $30-39 y$ & $40-49 y$ & $50-59 y$ & $60-69 y$ & $70-74 y$ \\
\hline \multicolumn{8}{|c|}{ Men } \\
\hline $0-3$ & $2.72 \pm 1.07$ & $2.81 \pm 1.03$ & $2.82 \pm 1.07$ & $2.57 \pm 1.11$ & $2.69 \pm 1.09$ & $2.77 \pm 0.96$ & $3.00 \pm 1.41$ \\
\hline $4-5$ & $3.01 \pm 1.06^{\mathrm{c}}$ & $3.06 \pm 1.00$ & $3.12 \pm 1.02$ & $2.92 \pm 1.00$ & $2.87 \pm 1.16$ & $3.12 \pm 1.06$ & $3.33 \pm 0.71$ \\
\hline $6-7$ & $3.34 \pm 1.00^{\mathrm{ab}}$ & $3.42 \pm 0.84$ & $3.05 \pm 1.15$ & $3.04 \pm 1.02^{\mathrm{a}}$ & $3.44 \pm 1.01^{\mathrm{ab}}$ & $3.45 \pm 0.99^{\mathrm{a}}$ & $3.20 \pm 0.86$ \\
\hline Total & $2.97 \pm 1.07$ & $3.01 \pm 1.01$ & $2.97 \pm 1.06$ & $2.79 \pm 1.06$ & $2.94 \pm 1.14$ & $3.15 \pm 1.04$ & $3.23 \pm 0.82$ \\
\hline F value & $22.757^{* * *}$ & 2.878 & 1.656 & $3.261^{*}$ & $9.153^{* * *}$ & $5.209^{* *}$ & 0.151 \\
\hline \multicolumn{8}{|c|}{ Women } \\
\hline $0-3$ & $2.81 \pm 1.07$ & $2.76 \pm 1.14$ & $2.87 \pm 1.07$ & $2.68 \pm 1.18$ & $2.80 \pm 0.97$ & $2.91 \pm 1.05$ & $3.50 \pm 0.58$ \\
\hline $4-5$ & $3.12 \pm 1.03^{\mathrm{c}}$ & $3.19 \pm 1.02^{\mathrm{c}}$ & $3.20 \pm 1.02$ & $3.12 \pm 1.06^{\mathrm{c}}$ & $2.94 \pm 1.05$ & $3.22 \pm 0.96$ & $3.60 \pm 0.70$ \\
\hline $6-7$ & $3.52 \pm 0.86^{\mathrm{ab}}$ & $3.63 \pm 0.63^{\mathrm{a}}$ & $3.11 \pm 1.20$ & $3.64 \pm 0.68^{\mathrm{ab}}$ & $3.52 \pm 0.91^{\mathrm{ab}}$ & $3.63 \pm 0.80^{\mathrm{ab}}$ & $3.45 \pm 0.80$ \\
\hline Total & $3.11 \pm 1.04^{\#}$ & $3.12 \pm 1.05$ & $3.10 \pm 1.06$ & $3.07 \pm 1.09$ & $3.00 \pm 1.04$ & $3.24 \pm 0.97$ & $3.50 \pm 0.74$ \\
\hline F value & $28.786^{* * *}$ & $7.012^{* *}$ & 2.094 & $10.089^{* * *}$ & $9.294^{* * *}$ & $6.648^{* *}$ & 0.127 \\
\hline
\end{tabular}

${ }^{\mathrm{a}} \mathrm{p}<0.05,6$ - 7 vs. 0 - 3; ${ }^{\mathrm{b}} \mathrm{p}<0.05,6$ - 7 vs. 4 - 5; ${ }^{\mathrm{c}} \mathrm{p}<0.05,4-5$ vs. 0 - 3; ${ }^{\#} \mathrm{p}<0.01$, women vs. men; ${ }^{* *} \mathrm{p}<0.01{ }^{* * *} \mathrm{p}<0.001$; Significant differences among the health practices groups measured using Tukey’s HSD test. 
Table 5. Mean BMI variable by health practices, age, and sex groups.

\begin{tabular}{|c|c|c|c|c|c|c|c|}
\hline $\begin{array}{l}\text { Number of health } \\
\text { practices }\end{array}$ & Total & $20-29 y$ & $30-39 y$ & $40-49 y$ & $50-59 y$ & $60-65 y$ & $70-74 y$ \\
\hline \multicolumn{8}{|c|}{ Men } \\
\hline $0-3$ & $24.20 \pm 3.70$ & $22.68 \pm 3.46$ & $24.19 \pm 3.87$ & $25.18 \pm 3.50$ & $24.58 \pm 3.79$ & $23.24 \pm 3.22$ & $24.92 \pm 0.95$ \\
\hline $4-5$ & $23.44 \pm 3.05^{\mathrm{c}}$ & $23.37 \pm 3.88$ & $23.01 \pm 3.09^{c}$ & $23.60 \pm 3.10^{c}$ & $23.50 \pm 2.76^{\mathrm{c}}$ & $23.61 \pm 2.81$ & $22.87 \pm 2.57$ \\
\hline $6-7$ & $22.44 \pm 2.53^{\mathrm{ab}}$ & $21.56 \pm 2.44$ & $21.57 \pm 2.03^{\mathrm{a}}$ & $23.03 \pm 3.47^{\mathrm{a}}$ & $22.32 \pm 2.31^{\mathrm{ab}}$ & $23.61 \pm 2.81$ & $22.96 \pm 1.92$ \\
\hline Total & $23.51 \pm 3.26$ & $22.85 \pm 3.58$ & $23.4 \pm 3.48$ & $24.22 \pm 3.40$ & $23.60 \pm 3.15$ & $22.79 \pm 2.57$ & $23.08 \pm 2.12$ \\
\hline F value & $19.559^{* * *}$ & 2.047 & $5.640^{* *}$ & $6.763^{* *}$ & $10.683^{* * *}$ & 1.630 & 0.793 \\
\hline \multicolumn{8}{|c|}{ Women } \\
\hline $0-3$ & $22.77 \pm 3.80$ & $21.42 \pm 4.13$ & $22.10 \pm 3.39$ & $22.95 \pm 4.18$ & $23.77 \pm 3.77$ & $23.06 \pm 2.72$ & $23.45 \pm 4.76$ \\
\hline $4-5$ & $21.90 \pm 3.07^{c}$ & $20.66 \pm 2.52$ & $21.03 \pm 2.83^{c}$ & $22.23 \pm 3.19$ & $22.26 \pm 2.83^{c}$ & $22.64 \pm 3.21$ & $24.50 \pm 4.92$ \\
\hline $6-7$ & $21.07 \pm 2.39^{\mathrm{ab}}$ & $20.48 \pm 2.86$ & $20.75 \pm 2.52^{\mathrm{a}}$ & $20.81 \pm 2.38^{\mathrm{a}}$ & $21.28 \pm 2.06^{\mathrm{a}}$ & $21.10 \pm 2.56^{\mathrm{ab}}$ & $22.02 \pm 1.87$ \\
\hline Total & $21.98 \pm 3.22$ & $20.86 \pm 3.15$ & $21.28 \pm 2.99$ & $22.22 \pm 3.45$ & $22.48 \pm 3.10$ & $22.42 \pm 3.06$ & $22.86 \pm 3.39$ \\
\hline F value & $18.934^{* * *}$ & 1.248 & $3.374^{*}$ & $4.650^{* *}$ & $12.980^{* * * *}$ & $5.922^{* *}$ & 2.039 \\
\hline
\end{tabular}

${ }^{a} \mathrm{p}<0.05,6-7$ vs. 0 - 3; ${ }^{\mathrm{b}}<<0.05,6$ - 7 vs. $4-5 ;{ }^{\mathrm{c}} \mathrm{p}<0.05,4$ - 5 vs. $0-3 ;{ }^{* *} \mathrm{p}<0.01 ;{ }^{* * *} \mathrm{p}<0.001$; Significant differences among the health practices groups measured using Tukey's HSD test.

life satisfaction, and BMI were better in the 6 - 7 group than in the 4 - 5 and 0 - 3 groups. There were no statistically significant differences in the $70-74$ age group (Tables 3-5).

Pearson's correlation analysis showed a significant positive correlation between perceived health status and health practices $(r=0.0 .229, p<0.001)$, life satisfaction $(r=0.279, p<0.001)$, social network $(r=0.089, p<$ $0.001)$, and employment $(\mathrm{r}=-0.123, \mathrm{p}<0.001)$; and a significant negative correlation for age $(\mathrm{r}=-0.058, \mathrm{p}<$ $0.01)$, BMI $(\mathrm{r}=-0.093, \mathrm{p}<0.001)$, and depression $(\mathrm{r}=-0.177, \mathrm{p}<0.001)$. There was a negative correlation between age and life satisfaction, but it was not statistically significant (Table 6).

A multiple stepwise regression analysis of the health practices scores was performed to determine which independent variables were predictors of perceived health status for all participants. With seven independent variables in the regression model, the analysis produced the following results: $14.1 \%(\mathrm{p}<0.01)$ for all participants, $17.5 \%(p<0.05)$ for men, and $12.3 \%(p<0.01)$ for women (Table 7$)$.

Several highly significant correlations were found for the independent variables; life satisfaction, seven health practices, employment status, and social network were found to have significant positive effects on levels of perceived health status. By contrast, age, depression, and BMI were found to have significant negative effects on perceived health status. BMI had no effect on levels of perceived health status among men. Both BMI and social network had no significant effect in women.

\section{Discussion}

Health is a multi-dimensional concept that is usually measured in terms of: 1) life expectancy (using international comparisons); 2) healthy life expectancy; 3) years of potential life lost (using international comparisons); 4) physical and mental illness; 5) self-rated health status; 6) limitation of activity; and 7) chronic disease prevalence [40]. More recently, self-rated health status has been used as a measure of how an individual perceives his or her health by rating it as excellent, very good, good, fair, or poor.

Perceived health status is a reliable and valid indicator for general health and many morbidities and mortality in adolescents [12] [41]-[43], students [44], working-age populations [3] [15] [45] [46], older adults [23] [47]-[49], middle-aged adults [50] [51], and general populations by follow-up study [25]. Perceived health status-also called self-rated health status, self-rated general health, or self-reported health—is a frequently used measure of subjective morbidity. There are two health status measures; one is a single-item self-perceived general health question, and the other is a multi-item index. If we compare the single-item and multi-item measures, the single-item (“All in all, would you say your health is excellent, good, fair, or poor?" and/or "very good, good, moderate, bad or very bad?”) is simpler and has been frequently used in research published recently in epidemi- 
Table 6. Pearson correlation matrix of variables.

\begin{tabular}{|c|c|c|c|c|c|c|c|c|c|}
\hline variable & 1 & 2 & 3 & 4 & 5 & 6 & 7 & 8 & 9 \\
\hline 1. Age & - & $0.112^{* * *}$ & $0.194^{* * *}$ & -0.039 & $-0.058^{* *}$ & $-0.107^{* * *}$ & $0.088^{* * *}$ & $-0.116^{* * *}$ & $-0.205^{* * *}$ \\
\hline 2. BMI & & - & $-0.198^{* * *}$ & -0.028 & $-0.093^{* * * *}$ & -0.029 & $0.062^{* *}$ & 0.012 & -0.009 \\
\hline 3. Seven health practices & & & - & $0.222^{* * *}$ & $0.229^{* * *}$ & $-0.100^{* *}$ & $0.116^{* * * *}$ & $-0.056^{* *}$ & $-0.131^{* * * *}$ \\
\hline 4. Life satisfaction & & & & - & $0.279^{* * * *}$ & $-0.177^{* * *}$ & $0.085^{* * *}$ & -0.010 & $0.057^{* *}$ \\
\hline 5. Perceived health status & & & & & - & $-0.109^{* * *}$ & $0.089^{* * * *}$ & 0.016 & $0.123^{* * *}$ \\
\hline 6. Depression & & & & & & - & $-0.002^{*}$ & $0.049^{*}$ & $0.068^{* *}$ \\
\hline 7. Social network & & & & & & & - & 0.025 & 0.021 \\
\hline 8. Family structure & & & & & & & & - & 0.023 \\
\hline 9. Employment & & & & & & & & & - \\
\hline
\end{tabular}

Table 7. Multiple analysis of perceived health status and life satisfaction for other variables.

\begin{tabular}{cccc}
\hline Independent variables & All & Men & Women \\
\hline Life satisfaction & $0.209^{* * *}$ & $0.219^{* * *}$ & $0.197^{* * *}$ \\
Seven health practices & $0.203^{* * * *}$ & $0.224^{* * *}$ & $0.177^{* * *}$ \\
Employment & $0.129^{* * *}$ & $0.112^{* * *}$ & $0.144^{* * *}$ \\
Age & $-0.093^{* * *}$ & $-0.135^{* * *}$ & $-0.060^{*}$ \\
Depression & $-0.072^{* * *}$ & $-0.062^{* * *}$ & $-0.083^{* *}$ \\
Social network & $0.051^{* *}$ & $0.140^{* * *}$ & - \\
BMI & $-0.041^{*}$ & - & - \\
$\mathrm{R}^{2}$ & $0.141^{* *}$ & $0.175^{*}$ & $0.123^{* *}$ \\
\hline
\end{tabular}

${ }_{\mathrm{p}}^{*}<0.05 ;{ }^{* *} \mathrm{p}<0.01 ;{ }^{* * *} \mathrm{p}<0.001$; using stepwise regression analysis.

ologic and public health journals. In some surveys, more than five answer categories have been used; other surveys use fewer categories. In our study, a four-answer question (“All in all, would you say your health is excellent, good, fair, or poor?” [23] [52]) was used to survey health status.

Lifestyle has been defined as any activity undertaken by an individual. It can include health behaviors and risk behaviors, which are both often related in clusters to a more complex pattern of behaviors referred to as lifestyle. An individual lifestyle assessment is usually used to self-report behaviors such as eating habits, smoking habits, drinking habits, nutrition, driving safety, sleep patterns, leisure-time activities, and physical activity. Although many previous studies have reported a relationship between lifestyle and perceived health status, there are many lifestyle assessment variables [26]-[36], and scales of perceived health status are also varied or complex [27] [28] [33] [36]. In this study, we reviewed previous studies, especially those of Breslow. Our objective was to clarify the relationship between perceived health status (excellent, good, fair, or poor) and Breslow's seven health practices among Japanese adults, to find effective and simple health behaviors for improved health as well as for epidemiological study.

With the single-item self-rated general health question, the respondents' answers are not only a reflection of their "objective" health status but are also influenced by the norms and expectations of individuals, groups, and societies about health. Kaplan [25] reported that there is a relationship among perceived health status, physical health status, and mortality. In that study, the variables of physical health status were constructed from individual reports of disability, chronic conditions, symptoms, and energy levels. Measuring those variables takes some time and involves complex analysis. It is neither convenient nor cost-effective for public health staff to collect such data in general community health care settings.

Nedra's study [37] on the relationship between health practices and mortality reported that men and women 
engaged in six or seven of the health practices described here had greater life expectancy than those practicing three or less [40]. Our data also show that those engaging in more than four practices have a higher perceived health status, greater life satisfaction, and a healthier BMI than those who only practice three or fewer.

The results of the Pearson's regression analysis found a significant relationship between perceived health status and these seven health practices, and also for BMI. The same was true in the multiple regression analyses, which indicated the independent impact of the seven practices and BMI on perceived health status. Furthermore, life satisfaction, employment, age, depression, and social network are significant factors in respondents' perceived health status.

\subsection{Limitations}

This study had several limitations. First, the questionnaire response rate was $45.1 \%$, which is lower than the typical 50\% - 70\% rate [52]. Previous studies have shown that there are various techniques to increase the response rate of mail surveys, for example, providing incentives for respondents, follow-up contact via telephone and postcard, and shorter questionnaires [53]-[55]. Although we used a kairanban (a regional newsletter and notice board) to remind respondents to return their questionnaires, we did not provide any incentive to do so. The six-page questionnaire contained more than 40 items; this may therefore be the reason for the low response rate. When compared with respondents, the small group of non respondents contained more young people (30.3\% were aged 20 - 39 years) and older people (33.3\% aged 70 - 74 years). Second, this study did not cover Japan's entire adult population because we did not survey those over 75 years old. Monitoring the health habits of older adults is an important job for community health nurses in Japan.

\subsection{Future}

It is clear that perceived health status is associated with the seven health practices in this study, and that regular engagement in more than four of these practices results in a higher perceived health status. However, further analyses would be valuable to examine this issue in greater detail. An example is investigation of which health practices should be included in the "more than four" group and which in the "less than four" group. The nature of the interaction between chronic condition variables with respect to their impact on perceived health status and health practices must be clarified and should be the subject of further exploration. It is also important to research the best way to encourage an environment in which to create good health habits in Japan.

\section{Conclusion}

Our findings demonstrate a strong relationship between perceived health status and Breslow's seven health practices. These results support the use of such practices to enhance perceived health status and to encourage good habits for improved health and longevity in the community.

\section{Acknowledgements}

We would like to thank all the participants in this study, and the technical support staff for data analysis and clerical support.

\section{References}

[1] Relloc, N.B. and Rreslow, L. (1972) Relationship of Physical Health Status and Health Practices. Preventive Medicine, 1, 409-421. http://dx.doi.org/10.1016/0091-7435(72)90014-X

[2] Kawada, T., Shinmyo, R.R. and Suzuki, S. (1994) Effects of Regular Health Practices on Subjective Evaluation of Health. Japan Journal of Industry Health, 36, 57-63. http://dx.doi.org/10.1539/joh1959.36.2_57

[3] Morimoto, K. (1991) The Significance and Prospect of Lifestyle Study. In: Morimoto, K., Ed., Lifestyle and HealthHealth Theory and Demonstrable Research, Igaku Syoin, Tokyo, 2-32. (In Japanese)

[4] Kawakami, N., Haratani, T., Kaneko, T. and Koizumi, A. (1987) Relationship between Health Practices and Depressive Mood among Industrial Workers. Japan Journal of Industry Health, 29, 55-63. (In Japanese) http://dx.doi.org/10.1539/joh1959.29.55

[5] Ezoe, A. and Morimoto, K. (1991) Quantitative Assessment of Lifestyle and Mental Health Status. Health Science, 8, 61-64. (In Japanese) 
[6] Kawada, T. and Suzuki, S. (1995) The Relationship between Being Satisfied with One’s Health, Good Health Practices and Personal Symptoms of Ill Health. Journal of Occupational Health, 37, 161-163. http://dx.doi.org/10.1539/sangyoeisei.37.3_161

[7] Nakayama, K., Yamaguchi, K., Maruyama, S. and Morimoto, K. (2001) The Relationship of Lifestyle Factors, Personal Character and Mental Health Status of Employees of a Major Japanese Electrical Manufacturer. Environmental Health and Preventive Medicine, 5, 144-149. http://dx.doi.org/10.1007/BF02918290

[8] Morimoto, K. (2000) Prevention of Lifestyle-Related Diseases-Prediction of Health Change and Disease Onset. Clinic All Round, 49, 2746-2750.

[9] Morimoto, K. (1987) Life Style and Health. Japanese Journal of Public Health, 51, 63-71.

[10] Seto, M. and Kanda, K. (1990) A Comparative Study of the Life-Style in the Healthy Young Persons and Elderly Healthy Persons. The Annual Reports of College of Medical Care and Technology, 11, 97-102.

[11] Takakura, M. and Matsuoka, Y. (1995) Relationship between Health Practices and Perceived Health Status of University Students. University of the Ryukyus Repository, 47, 125-132.

[12] Muramatsu, T., Muramastu, S., Kataoka, S. and Kaneko, O. (1996) Smoking among Young Female and Their Lifestyle. Bulletin of Aichi University of Education Educational Sciences, 45, 39-44.

[13] Masumoto, T. (2001) Health Status among Residents Based on Salutogenic Model. Ritsumeikan Review of Industrial Society, 36, 53-73.

[14] Tokuchin, A. and Kosaka, Y. (2010) An Investigation into Ways to Improve Life Habits of Female Students. Human and Environment, 3, 1-6.

[15] Marutama, S. and Morimoto, K. (1997) The Effects of Lifestyle and Type a Behavior on the Life-Stress Process. Environmental Health and Preventive Medicine, 37, 327-336.

[16] Sakurai, H. (2001) Health Japan 21. The Japan Medical Association Journal, 26, 1542-1543.

[17] Annual Health (1997) Labor and Welfare Report, Japan.

[18] Gibson Parrish, R. (2010) Measuring Population Health Outcomes. Preventing Chronic Disease, 7, 1-11.

[19] Thacker, S.B., Stroup, D.F., Carande-Kulis, V., Maeks, J.S., Roy, K. and Gerberding, J.L. (2006) Measuring the Public’s Health. Public Health Reports, 121, 14-22.

[20] Reidpath, D.D. (2003) Infant Mortality Rate as an Indicator of Population Health. Journal of Epidemiology Community Health, 57, 344-346. http://dx.doi.org/10.1136/jech.57.5.344

[21] Dempsey, M. (1947) Decline in Tuberculosis; the Death Rate Fails to Tell the Entire Story. American Review of Tuberculosis, 56, 157-164.

[22] Martini, C.J. and McDowell, I. (1976) Health Status: Patient and Physician Judgments. Health Service Research, 11, 508-515.

[23] Idler, E.L. and Benyamini, Y. (1997) Self-Rated Health and Mortality: A Review of Twenty-Seven Community Studies. Journal of health and Social Behavior, 38, 21-37. http://dx.doi.org/10.2307/2955359

[24] Ven Ginneken, J.K. and Groenewold, G. (2012) A Single- vs. Multi-Item Self-Rated Health Status Measure: 21Country Study. The Open Public Health Journal, 5, 1-9. http://dx.doi.org/10.2174/1874944501205010001

[25] Kaplan, G.A. and Camacho, T. (1983) Perceived Health and Mortality: A Nine-Year Follow-Up of the Human Population Laboratory Cohort. American Journal of Epidemiology, 117, 292-304.

[26] Pope, C.R. (1982) Life-Style, Health Status and Medical Care Utilization. Medical Care, 20, 402-413. http://dx.doi.org/10.1097/00005650-198204000-00005

[27] Kawada, T., Shinmyo, R.R. and Suzuki, S. (1993) Effects of Regular Health Practices on Subjective Evaluation of Health. Japan Society for Occupational Health, 36, 57-63.

[28] Ohta, A., Takeuchi, K., Yosiaki, S. and Suzuki, S. (1998) Differences in Lifestyle and Perceived Health in Different Occupations in a Community. Journal of Occupation Health, 40, 325-333. http://dx.doi.org/10.1539/joh.40.325

[29] Johansson, S.-E. and Sundquist, J. (1999) Change in Lifestyle Factors and Their Influence on Health Status and All-Cause Mortality. International Epidemiological Association, 28, 1073-1080. http://dx.doi.org/10.1093/ije/28.6.1073

[30] de Groot, L.C.P.M.G., Verheijden, M.W., de Henauw, S., Schroll, M. and van Staveren, W.A. (2004) Lifestyle, Nutritional Status, Health, and Mortality in Elderly People across Europe: A Review of the Longitudinal Results of the SENECA Study. Journal of Gerontology: Medical Sciences, 59, 1277-1284. http://dx.doi.org/10.1093/gerona/59.12.1277

[31] Wang, N., Iwasaki, M., Otani, T., Hayashi, R., Miyazaki, H., Xiao, L., Yosiaki, S., Suzuki, S., Koyama, H. and Sakamaki, 
T. (2005) Perceived Health as Related to Income, Socio-Economic Status, Lifestyle, and Social Support Factors in a Middle-Aged Japanese. Journal of Epidemiology, 15, 155-162.

http://dx.doi.org/10.2188/jea.15.155

[32] Enstrom, J.E. and Breslow, L. (2007) Lifestyle and Reduced Mortality among Active Califonia Mormons, $1980-2004$. Preventive Medicine, 46, 133-136. http://dx.doi.org/10.1016/j.ypmed.2007.07.030

[33] Angyan, L., Antal, C., Teczel, T. and Karsai, I. (2008) Self-Reported Health Status and Lifestyle of University Students. Hungarian Medical Journal, 2, 417-426. http://dx.doi.org/10.1556/HMJ.2.2008.3.8

[34] Rogers, L.Q., Courneya, K.S., Paragi-Gururaja, R., Markwell, S.J. and Imeokparia, R. (2008) Lifestyle Behaviors, Obesity, and Perceived Health among Men with and without a Diagnosis of Prostate Cancer: A Population-Based, Cross-Sectional Study. BMC Public Health, 8, 23. http://www.biomedcentral.com/1471-2458/8/23 http://dx.doi.org/10.1186/1471-2458-8-23

[35] Colzani, E., Bonazzi, C. and Corno, G.D. (2010) Health Life Style and Perceived Health Status in the General Population of a Northern Italian Health District: A Cross-Sectional Study. Italian Journal of Public Health, 7, 235-242.

[36] Otonari, J., Nagano, J., Morita, M., Budhahoki, S., Tashiro, N., Toyomura, K., Kono, S., Imai, K., Ohnaka, K. and Takayanagi, R. (2012) Neuroticism and Extraversion Personality Traits, Health Behaviors, and Subjective Well-Being: The Fukuoka Study (Japan). Quality of Life Research, 21, 1847-1855. http://dx.doi.org/10.1007/s11136-011-0098-y

[37] Belloc, N.B. (1973) Relationship of Health Practices and Mortality. Preventive Medicine, 2, 67-81. http://dx.doi.org/10.1016/0091-7435(73)90009-1

[38] Belloc, N.B., Breslow, L. and Hochstim, J.R. (1971) Measurement Physical Health in a General Population Survey. American Journal of Epidemiology, 93, 328-336.

[39] Chang, C.N., Miyakita, T., Harada, K., Ohmori, S. and Ueda, A. (2000) Determinants of Life Satisfaction among Japanese Agricultural Workers. Environmental Health Preventive Medicine, 5, 25-30. http://dx.doi.org/10.1007/BF02935912

[40] Healthy People 2020 (2015) General Health Status. https://www.healthypeople.gov/2020/about/foundation-health-measures/general-health-status/

[41] Afridi, A.A.K., Motwani, K., Khawaja, S., Khoja, A.A., Fatmi, Z., Azam, I. and Kadir, M.M. (2013) Self-Perceived Health among School Going Adolescents in Pakistan: Influence of Individual, Parental and Life Style Factors. Global Journal of Health Science, 5, 71-78.

[42] Piko, B.F. (2007) Self-Perceived Health among Adolescents: The Role of Gender and Psychosocial Factors. European Journal Pediatrics, 166, 701-708. http://dx.doi.org/10.1007/s00431-006-0311-0

[43] Fosse, N.E. and Haas, S.A. (2009) Validity and Stability of Self-Reported Health among Adolescents in a Longitudinal, National Representative Survey. Pediatrics, 123, 496-501. http://dx.doi.org/10.1542/peds.2008-1552

[44] Piko, B. (2000) Health-Related Predictors of Self-Perceived Health in a Student Population: The Importance of Physical Activity. Journal of Community Health, 25, 125-137. http://dx.doi.org/10.1023/A:1005129707550

[45] Freyer-Adam, J., Gaertner, B., Tobschall, S. and John, U. (2011) Health Risk Factors and Self-Rated Health among Job-Seekers. MBC Public Health, 11, 659. http://www.biomedcentral.com/1471-2458/11/659 http://dx.doi.org/10.1186/1471-2458-11-659

[46] Okano, G., Miyake, H. and Mori, M. (2003) Leisure Time Physical Activity as a Determinant of Self-Perceived Health and Fitness in Middle-Aged Male Employees. Journal of occupational Health, 45, 286-292. http://dx.doi.org/10.1539/joh.45.286

[47] Friedsam, H.J. and Martin, H.W. (1963) A Comparison of Self and Physicians' Health Ratings in an Older Population. Journal of Health \& Human Behavior, 4, 179-183. http://dx.doi.org/10.2307/2948660

[48] Pu, C., Tang, G.-J., Huang, N. and Chou, Y.-J. (2011) Predictive Power of Self-Rated Health for Subsequent Mortality Risk during Old Age: Analysis of Data from a Nationally Representative Survey of Elderly Adults in Taiwan. Journal of Epidemiology, 21, 278-284. http://dx.doi.org/10.2188/jea.JE20100131

[49] Mossey, J.M. and Shapiro, E. (1982) Self-Rated Health: A Predictor of Mortality among the Elderly. American of Journal of Public Health, 72, 800-808. http://dx.doi.org/10.2105/AJPH.72.8.800

[50] Norberg, M., Lindvall, K., Jenkins, P.L., Emmelin, M., Lonnberg, G. and Nafziger, A.N. (2011) Self-Rated Health Does Not Predict 10-Year Weight Change among Middle-Aged Adults in a Longitudinal Population Study. BMC Public Health, 11,748. http://www.biomedcentral.com/1471-2458/11/748 http://dx.doi.org/10.1186/1471-2458-11-748

[51] Kaczmarek, M. and Skrzypczak, M. (2012) Perceived Health Status among Middle-Aged Polish People in Relation to Selected Demographic and Social Factors. Anthropological Review, 75, 93-105. 
http://dx.doi.org/10.2478/v10044-012-0008-0

[52] (2014) Response Rates on Mail Surveys. http://www.pra.ca/resources/pages/files/technotes/rates e.pdf

[53] Church, A.H. (1993) Estimating the Effect of Incentives on Mail Survey Response Rates: A Meta-Analysis. Public Opinion Quarterly, 57, 62-79. http://dx.doi.org/10.1086/269355

[54] Edwards, P., Roberts, I. and Clarke, M. (2002) Increasing Response Rates to Postal Questionnaires: Systematic Review. British Medical Journal, 324, 1183-1191. http://dx.doi.org/10.1136/bmj.324.7347.1183

[55] Edwards, P., Roberts, I. and Clarke, M. (2007) Methods to Increase Response Rates to Postal Questionnaires. Cochrane Database Systematic Review, 2, 53-54. http://dx.doi.org/10.1002/14651858.mr000008.pub3 